\title{
Exceptional sequence of severe thunderstorms and related flash floods in May and June 2016 in Germany - Part 1: Meteorological background
}

\author{
David Piper ${ }^{1,4}$, Michael Kunz ${ }^{1,4}$, Florian Ehmele ${ }^{1,4}$, Susanna Mohr ${ }^{1,4}$, Bernhard Mühr ${ }^{1,4}$, Andreas Kron ${ }^{2,4}$, and \\ James Daniell ${ }^{3,4}$ \\ ${ }^{1}$ Institute of Meteorology and Climate Research (IMK-TRO), Karlsruhe Institute of Technology (KIT), Karlsruhe, Germany \\ ${ }^{2}$ Institute for Water and River Basin Management (IWG), Karlsruhe Institute of Technology (KIT), Karlsruhe, Germany \\ ${ }^{3}$ Geophysical Institute (GPI), Karlsruhe Institute of Technology (KIT), Karlsruhe, Germany \\ ${ }^{4}$ Center for Disaster Management and Risk Reduction Technology (CEDIM), Karlsruhe, Germany
}

Correspondence to: Michael Kunz (michael.kunz@kit.edu)

Received: 17 August 2016 - Published in Nat. Hazards Earth Syst. Sci. Discuss.: 8 September 2016

Revised: 1 December 2016 - Accepted: 4 December 2016 - Published: 22 December 2016

\begin{abstract}
During a 15-day episode from 26 May to 9 June 2016, Germany was affected by an exceptionally large number of severe thunderstorms. Heavy rainfall, related flash floods and creek flooding, hail, and tornadoes caused substantial losses running into billions of euros (EUR). This paper analyzes the key features of the severe thunderstorm episode using extreme value statistics, an aggregated precipitation severity index, and two different objective weathertype classification schemes. It is shown that the thunderstorm episode was caused by the interaction of high moisture content, low thermal stability, weak wind speed, and large-scale lifting by surface lows, persisting over almost 2 weeks due to atmospheric blocking.

For the long-term assessment of the recent thunderstorm episode, we draw comparisons to a 55-year period (1960-2014) regarding clusters of convective days with variable length (2-15 days) based on precipitation severity, convection-favoring weather patterns, and compound events with low stability and weak flow. It is found that clusters with more than 8 consecutive convective days are very rare. For example, a 10-day cluster with convective weather patterns prevailing during the recent thunderstorm episode has a probability of less than $1 \%$.
\end{abstract}

\section{Introduction}

Between the end of May and mid-June 2016, Germany and large parts of central and southern Europe were affected by an exceptionally large number of severe convective storms and related extremes such as heavy rainfall, hail, and tornadoes (Fig. 1). Rain totals exceeding $100 \mathrm{~mm}$ within a few hours at several locations in Germany triggered various flash floods and floods mainly in small catchments. In the town of Braunsbach in the federal state of Baden-Württemberg, for example, a severe flash flood on 29 May with a height of up to $3.5 \mathrm{~m}$ caused serious damage to more than 80 buildings, of which five were completely lost (Daniell et al., 2016). Only 3 days later on 1 June, extreme rain in the district of Rottal-Inn in the south of Bavaria evoked a sudden and dramatic rise in the levels of several creeks such as the Simbach, where the height increased from $20 \mathrm{~cm}$ to more than $5 \mathrm{~m}$ within only $12 \mathrm{~h}$. Subsequently, the village Simbach am Inn experienced the largest flooding in history. Some of the thunderstorms during the 2 weeks also produced hail with diameters between 0.5 and $5 \mathrm{~cm}$. A total of 12 tornadoes in 8 days with intensities between F0 and F1 on the Fujita intensity scale, were recorded and confirmed by the European Severe Weather Database (ESWD; Dotzek et al., 2009).

The severe thunderstorms caused substantial damage to buildings, infrastructures, transportation networks, and crops. A large number of roads and railroads were blocked or severely damaged, and some villages experienced power out- 


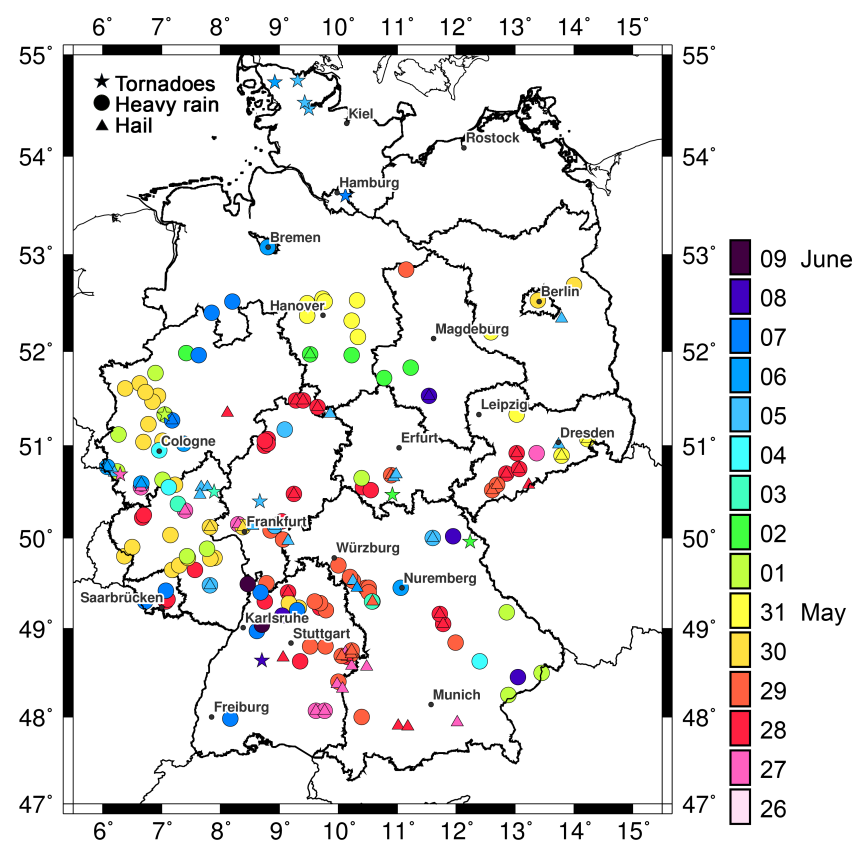

Figure 1. Phenomena associated with severe convective storms between 26 May and 9 June 2016 collected from various sources of information (European Severe Weather Database, newspaper articles, weather services; heavy rain $\bullet$, hail $\Delta$, and tornadoes $\star$ ).

ages over a couple of days. Flooded regions such as the district of Rottal-Inn in Bavaria were completely trapped by the water masses and cut off from the outside world. According to MunichRe (2016), the overall losses associated with the severe convective storms in Europe totaled EUR 5.4 billion, of which EUR 2.7 billion were insured. In Germany, economic losses accounted for EUR 2.6 billion with insured losses of EUR 1.2 billion (GDV, 2016).

The large number of severe thunderstorms developed in an environment with moist and unstable air masses that persisted over almost 2 weeks. A large-scale ridge (upper-level high-pressure system) stretching from Great Britain to Iceland and central Scandinavia caused a blocking situation and hampered the exchange of air masses during the episode. The pressure gradient and the resulting wind speed in the lower troposphere were very weak, particularly in the second half of the storm episode. Consequently, thunderstorms were almost stationary, resulting in large precipitation accumulations in local areas.

The objectives of this paper are to highlight the meteorological conditions that were decisive for the thunderstorm episode, to estimate the severity of the recorded rain totals, and to put the event into historical context. Since information about thunderstorm occurrence is not available over a sufficiently long period, statistical analyses are based on different proxies that estimate the convective potential of the atmosphere: large-scale weather patterns derived from reanalysis data and convective parameters obtained from vertical pro- files of radio soundings. Another purpose of our study is to estimate empirical probability distributions with respect to the variable cluster length of days with convective weather situations using dichotomous parameters such as convectionfavoring weather types or areal-related precipitation severity index.

While this paper focuses on the meteorological aspects of the severe thunderstorm episode, Part 2 (Daniell et al., 2016) will discuss the impact of selected flash floods in BadenWürttemberg and will present a simplified method to estimate losses from flash floods. All investigations were conducted within the frame of the Forensic Disaster Analysis (FDA) approach in near real time, which is the main research strategy of the Center of Disaster Management and Risk Reduction Technology (www.cedim.de; Kunz et al., 2013).

The paper is structured as follows: Sect. 2 presents the different data sets that are used and the methods applied. Section 3 discusses the synoptic background, including precipitation observations and the respective probabilities in a long-term perspective. In Sect. 4, we assess the persistence of certain clusters of days with convection-favoring conditions and estimate their occurrence over the last 5 decades. Lastly, Sect. 5 briefly summarizes the main results and gives some conclusions.

\section{Data and methods}

The episode with an exceptional number of severe thunderstorms extended from 26 May to 9 June 2016 (hereafter referred to as STE16). For the long-term classification of STE16, occurrence probabilities for precipitation, atmospheric stability, and large-scale weather patterns were assessed with respect to the 55-year period 1960-2014 (C20/21) for the summer half year (SHY) from April to September. The study domain for the statistical analyses comprises the whole area of Germany south of $52^{\circ} \mathrm{N}$ (in case of model data, also adjacent countries), where most of the convective events occurred (see Fig. 1).

\subsection{Observational data}

\subsubsection{Precipitation}

Statistical rainfall analyses are based on $24 \mathrm{~h}$ REGNIE totals (REGionalisierte NIEderschläge, regionalized precipitation) provided by the German Weather Service (DWD). REGNIE is a gridded data set based on several thousand climate stations (RR collective). Selected station data are interpolated to a regular grid considering elevation, exposition, and climatology (Rauthe et al., 2013). The REGNIE area contains 611 grid points in west-east directions with $5.83^{\circ} \mathrm{E} \leq \phi \leq 16^{\circ} \mathrm{E}$ and 971 grid points in north-south directions with $47^{\circ} \mathrm{N} \leq \theta \leq 55.08^{\circ} \mathrm{N}$ ( $\phi$ is longitude; $\theta$ is latitude), but it only covers Germany. The spatial resolution is approximately $1 \mathrm{~km}^{2}$. It should be noted that REGNIE data 
are not homogeneous due to the temporal variability of the number of rain gauges considered.

In addition to REGNIE, we also used data from selected rain gauges of DWD stations with hourly resolution. For each day during STE16, we chose the rain gauge with the highest observed $24 \mathrm{~h}$ total. The observation time period for $24 \mathrm{~h}$ totals (both REGNIE and rain gauges) is from 06:00 to 06:00 UTC on the next day, but values are backdated in order to conform with the usual calendar days.

\subsubsection{Lightning}

Lightning data for 2001-2014 (SHY) were obtained from the German detection network BLIDS (Blitz-InformationsDienst Siemens), which is integrated in the European EUCLID (European Cooperation for Lightning Detection) network (Schulz et al., 2016). We only considered cloud-toground flashes (CG) to define convective days, without further distinguishing among polarity and peak current. BLIDS data are provided in a spatial resolution of $1 \mathrm{~km}$ and a temporal resolution of $1 \mathrm{~ms}$ (Drüe et al., 2007).

\subsubsection{Radio soundings}

Atmospheric conditions prevailing during STE16 and C20/21 were estimated from vertical profiles of temperature, moisture, and wind at four radio sounding stations in western and southern Germany: Essen $\left(51.41^{\circ} \mathrm{N}, 6.97^{\circ} \mathrm{E}\right)$, IdarOberstein $\left(49.70^{\circ} \mathrm{N}, 7.33^{\circ} \mathrm{E}\right)$, Stuttgart $\left(48.83^{\circ} \mathrm{N}, 9.20^{\circ} \mathrm{E}\right)$ and Munich $\left(48.24^{\circ} \mathrm{N}, 11.55^{\circ} \mathrm{E}\right)$. The profiles were provided by the Integrated Global Radiosonde Archive (IGRA) from the National Climatic Data Center (Durre et al., 2006). For the assessment of thermal stability, we used the surfacebased lifted index (SLI) and the convective available potential energy (CAPE). Both quantities have been identified in various studies to represent atmospheric stability well (Davis et al., 1997; Haklander and van Delden, 2003; Manzato, 2003; Kunz, 2007; Mohr and Kunz, 2013).

Since the movement of thunderstorms is controlled to a large degree by the wind vector at mid-tropospheric levels (depending on the vertical extent of the cell), we also considered wind speed and direction at $500 \mathrm{hPa}$.

\subsection{Model data}

The study domain for the model data is slightly extended to the border regions and covers the area of $5.5^{\circ} \mathrm{E} \leq \phi \leq 15.0^{\circ} \mathrm{E}, 47.5^{\circ} \mathrm{N} \leq \theta \leq 52.0^{\circ} \mathrm{N}$. Only data sets at 12:00 UTC were considered since they best mirror the prevailing convective conditions. Model data were used to estimate the large-scale weather situation during both STE16 and C20/21.

\subsubsection{CoastDat2}

The CoastDat2 reanalysis was employed here for investigating long-term convection-favoring conditions. The reanalysis was carried out by the Helmholtz-Zentrum Geesthacht Centre for Materials and Coastal Research in Germany (Geyer and Rockel, 2013; Geyer, 2014). CoastDat2 is based on the COSMO (Consortium for Small-Scale Modelling) model in climate mode, COSMO-CLM Version 4.8 (Rockel et al., 2008), and it uses the National Centers for Environmental Prediction-National Center for Atmospheric Research reanalysis (NCEP/NCAR1; Kalnay et al., 1996) as forcing, which in consequence of the almost constant data assimilation only exhibits a small trend. The model output is available for the entire European domain in a resolution of $0.22^{\circ}$, with 40 vertical model layers from 1948 (including 3 years spin-up time) until today.

\subsubsection{CFSv2 operational analysis}

Since CoastDat 2 data are not available for STE16 yet, we estimated prevailing weather patterns from Climate Forecast System (CFSv2) Operational Analysis data, which have been in operation since April 2011 as the successor of the Climate Forecast System Reanalysis (CFSR; Saha et al., 2010; Saha et al., 2011; Saha et al., 2014). The CFSv2 data are produced under guidance of the National Centers for Environmental Prediction (NCEP) and offer hourly data with a global horizontal resolution of $0.5^{\circ}$.

\subsection{Objective weather types of DWD}

The objective weather-type classification (OWLK) designed by DWD (Dittmann, 1995; Bissolli and Dittmann, 2001) differentiates between 40 weather patterns by quantifying three model parameters in a dichotomous scheme: (i) mean flow direction AA at $700 \mathrm{hPa}$ with the possibilities of SW, NW, NE, SE, and an indefinite type XX, (ii) cyclonality CY as the product of geostrophic vorticity and Coriolis parameter at low $(950 \mathrm{hPa})$ and mid-tropospheric levels $(500 \mathrm{hPa})$, yielding either cyclonic (C) or anticyclonic (A) flow, and (iii) humidity index HI represented by the precipitable water with the climatological daily average removed; positive and negative anomalies are denoted by $\mathrm{M}$ (moist) and D (dry).

The continuous grid point values contained in the reference domain are converted into one scalar number for each day and each parameter, which is mapped on a categorical variable in each case using previously defined thresholds. The four variables are concatenated forming a character code:

AA CY 950 hPa $\mathrm{CY}_{500 \mathrm{hPa}} \mathrm{HI}$.

For example, the pattern SWCAM refers to a mainly southwesterly flow, cyclonic and anticyclonic at $950 \mathrm{hPa}$ and $500 \mathrm{hPa}$, respectively, and a higher moisture content compared to climatology. 
Grid points near the center of the domain are weighted by a factor of 3 , those located near the margins by a factor of 1 , and all points in an interjacent zone by a factor of 2 , so as to restrict the influence of the outer areas. In this paper, the classification results obtained by DWD are used, which rely on the reference domain defined by Dittmann (1995) comprising Germany and parts of the neighboring countries.

Several studies have established a relationship between specific OWLK types and convective activity in terms of severe hailstorms (Kapsch et al., 2012; Mohr et al., 2015) or tornadoes (Bissolli et al., 2007). The advantages of OWLK compared to subjective methods such as the well-known classification of Hess and Brezowsky (HB, 1977) are the nonambiguous assignment criteria and the automated categorization procedure (Philipp et al., 2010). Even though the Low Central Europe (Tief Mitteleuropa, TM) circulation pattern prevailed on 6 days according to $\mathrm{HB}$, this pattern is usually not related to severe convection, but to persistent advective precipitation such as during the 2002 and 2013 German floods. Hence, we decided not to investigate HB further in this paper.

\subsection{Convective weather types}

It can be shown that OWLK only has limited skill regarding the identification of ambient conditions favorable for convective activity since it mainly aims at classifying the synoptic situation in general. Based on the methodical approach of OWLK, we therefore developed a new objective weathertype classification (conOWLK) with a special focus on convection. This scheme consists of four parameters: equivalent potential temperature at $850 \mathrm{hPa}$, precipitable water, surfacebased lifted index (SLI), and vertical velocity $w$ at $500 \mathrm{hPa}$. In the former two cases, we removed the average annual cycle by subtracting the 10-day running mean over the average daily values. The parameter values for a respective day are obtained analogously to OWLK by calculating the weighted areal mean over a rectangle now enclosing the study domain defined in Sect. 2.2.

The continuous variables are transformed into discrete ones using trichotomous parameters instead of dichotomous ones as for OWKL, allowing those values that can not be allocated clearly to one of the two original classes to be comprised by a third, neutral class (abbreviated as X). The thresholds are determined so as to distinguish best between conditions favoring and inhibiting convection, which is assessed by categorical verification with respect to lightning data. For this purpose, we calculated the distribution of the Heidke Skill Score (HSS) on a large range of possible threshold values for each parameter separately and chose the two values as thresholds where HSS equals its $90 \%$ quantile.

Convection-favoring weather types among the total of 81 classes were verified and identified against convective days according to BLIDS data using categorical verification. In this study, we categorize a specific day as convective if the flash number inside the inner weighting zone (see above) exceeds its $75 \%$ quantile. These thunderstorm-related types are characterized by relatively warm $(\mathrm{W})$ and moist $(\mathrm{M})$ conditions with instability (I) and either lifting (L) or no vertical motion (X) present, yielding the two codes WMIL and WMIX. Conversely, the two weather types inhibiting convection are given by the codes CDSS and CDSX (cold, dry, stable, and subsidence or no vertical motion). All other types are referred to as neutral.

Since the objective of conOWLK is to identify ambient conditions that imply a very high chance for the development of convection, a significant number of events are missed. Therefore, it is reasonable to additionally implement a less strict classification. This is done by developing a multivariate statistical model based on quadratic discriminant analysis (qdaOWLK). After the initial learning phase, it assigns a particular day to one of the groups convective day (yes or no) depending on the values of four continuous input variables, which are represented by the spatially averaged parameters used in conOWLK.

First, qdaOWLK is calibrated using CoastDat2 reanalysis and lightning data (2001-2014). These learning data are divided into two subsets corresponding to the same groups of convective and non-convective days, as were defined in the context of conOWLK, and which can be characterized by two different multivariate probability density distributions (Marinell, 1998). Based on this partitioning, an assignment rule in terms of a discriminant function is developed, which will be used to classify the days before 2001 for which lightning data are not available for.

Since covariance matrices differ significantly between both subsets (heteroscedasticity), quadratic instead of linear discriminant analysis has to be performed (Sánchez et al., 1998). Applying a Kolmogorov-Smirnov test to the time series of the four parameters yields significant deviations from the normal distribution. Therefore, data are normalized using a Yeo-Johnson power transformation (Yeo and Johnson, 2000). In this study, the quadratic discriminant function $\delta$ is derived using a maximum likelihood criterion (Sánchez et al., 1998). Hence, an arbitrary entity is assigned to the group exhibiting the higher value of the likelihood function $L_{m}$ with $m \in\{0,1\}$, corresponding to the populations of non-convective and convective days.

It can be shown that $\delta$ is computed from the input data vector $\boldsymbol{x}$ for a particular day by

$$
\begin{aligned}
\delta & =\frac{1}{2} \boldsymbol{x}^{T}\left(\Sigma_{0}^{-1}-\Sigma_{1}^{-1}\right) \boldsymbol{x}+\boldsymbol{x}^{T}\left(\Sigma_{1}^{-1} \boldsymbol{\mu}_{\mathbf{1}}-\Sigma_{0}^{-1} \boldsymbol{\mu}_{\mathbf{0}}\right) \\
& +\frac{1}{2} \boldsymbol{\mu}_{\mathbf{0}}^{T} \Sigma_{0}^{-1} \boldsymbol{\mu}_{\mathbf{0}}-\frac{1}{2} \boldsymbol{\mu}_{\mathbf{1}}^{T} \Sigma_{1}^{-1} \boldsymbol{\mu}_{\mathbf{1}}+\frac{1}{2} \ln \left(\frac{\left|\Sigma_{0}\right|}{\left|\Sigma_{1}\right|}\right),
\end{aligned}
$$

where $\Sigma_{m}$ represents the covariance matrix of population $m$, the superscript -1 denotes the inverse matrix, and $\mu_{\mathrm{m}}$ is the respective sample mean vector. Due to

$\delta=\ln \left[L_{1}(\boldsymbol{x})\right]-\ln \left[L_{0}(\boldsymbol{x})\right]$, 
an arbitrary day is classified as convective if $\delta>0$.

Model performance is assessed by means of leave-one-out cross-validation (Wilks, 1995). Here, the discriminant function is computed from the sample of training data excluding the first day, which is then classified by the model. For a sample of size $n$ this procedure is conducted $n$ times shifting the day excluded by one step each time. As a result, the $n$ predictions for convective day (yes or no) are compared with the actual incidences using categorical verification.

\subsection{Return periods}

To estimate statistical return periods of precipitation totals $R$, we applied the classical generalized extreme value (GEV) distribution. Most appropriate for precipitation statistics is the Fisher-Tippett type I (also known as Gumbel) distribution (Wilks, 1995), with a cumulative distribution function (CDF) of

$F(R)=\exp \left[-\exp \left(\frac{\zeta-R}{\beta}\right)\right]$,

where $\beta$ and $\zeta$ are scale and location parameter, respectively. The two free parameters of the CDF are estimated by the method of moments (Fisher and Tippett, 1928; Gumbel, 1958) using annual rainfall maxima during C20/21:

$\beta=\frac{\sigma \sqrt{6}}{\pi}, \quad \zeta=\bar{R}-\gamma \cdot \beta$,

where $\bar{R}$ is the sample mean, $\sigma$ the sample standard derivation, and $\gamma$ the Euler-Mascheroni constant $(\approx 0.5772)$.

The CDF describes the probability of occurrence $P$ of a value $R$ beneath a threshold $R_{\text {trs }}: F(R)=P\left(R<R_{\text {trs }}\right)$. Conversely, the return period $t_{\mathrm{RP}}$ is related to the probability of threshold exceedance $P\left(R \geq R_{\mathrm{trs}}\right)=t_{\mathrm{RP}}^{-1}$. Therefore, the CDF can be written as $F(R)=1-t_{\mathrm{RP}}^{-1}$. The resulting equation for the return period $t_{\mathrm{RP}}$ is

$t_{\mathrm{RP}}(R)=\left[1-\exp \left(-\exp \left(\frac{\zeta-R}{\beta}\right)\right)\right]^{-1}$.

\subsection{Heavy rainfall and precipitation severity index}

Heavy rainfall is usually defined either by the exceedance of appropriate percentiles (e.g., 99 or $99.9 \%$, see below) or by using a fixed threshold as a function of duration. In the latter case, we considered the criterion according to Wussow (1922):

$N_{\mathrm{cr}}=\sqrt{5 \cdot D}$

with the critical rain rate $N_{\text {cr }}$ representing a threshold for heavy convective rainfall for conditions prevailing in central Europe (Germany) with duration $D$ (in minutes) between $30 \mathrm{~min}$ and $24 \mathrm{~h}$. The Wussow criterion is only considered for the assessment of the station observations (Table 2).
Table 1. Classification results during STE16 based on OWLK and conOWLK using the character coding scheme defined in the text (Sect. 2.3 and 2.4).

\begin{tabular}{lcc}
\hline Date & OWLK & conOWLK \\
\hline 26 May & SWCCM & XDXD \\
27 May & SWCCM & WMID \\
28 May & SWCCM & WMIL \\
29 May & SECCM & WMIL \\
30 May & XXCCM & WMID \\
31 May & XXCCM & WMXD \\
1 June & XXCCM & WMXL \\
2 June & XXCCM & WMID \\
3 June & NECCM & WMIL \\
4 June & XXCCM & WMIX \\
5 June & XXAAM & WMIL \\
6 June & XXAAM & WXID \\
7 June & XXAAM & WDID \\
8 June & NWCAM & WMIL \\
9 June & NWACD & CDXD \\
\hline
\end{tabular}

Furthermore, the severity of past rain events is assessed by considering both intensity and spatial extent in terms of the precipitation severity index PS:

$\mathrm{PS}_{\xi}^{k}=\frac{1}{\Gamma} \sum_{i, j}\left(R_{i, j}^{k} \times F_{R}\right) \mid R_{i, j}^{k} \geq R_{i, j}^{\xi}$,

where $R_{i, j}$ represent the rain totals at REGNIE grid points $(i, j), k$ denotes a certain day, $F_{R}$ is the area of the REGNIE grid points $\left(=1 \times 1 \mathrm{~km}^{2}\right), \Gamma$ is the size of the investigation area, and $\xi$ are the 99 or $99.9 \%$ percentiles of the distribution function quantified independently at all grid points during C20/21. In this formulation, all totals are accumulated that are equal to or exceed the value of the 99 or $99.9 \%$ percentile, respectively, at the respective points. Dividing the accumulated totals by the size of the investigation area gives the precipitation severity index PS in $\mathrm{m}^{3}$ water. A similar version of PS was applied for the comparison of historic large-scale flood events by Schröter et al. (2015).

Whereas the $99 \%$ percentile (1.83th largest total in a year on average) may contain advective precipitation as well, the $99.9 \%$ percentile ( 0.18 th largest total) mainly considers heavy convective rainfall. Within the investigation area, the $99 \%(99.9 \%)$ percentiles vary between $15 \mathrm{~mm}(30 \mathrm{~mm})$ over the northern lowlands and almost $60 \mathrm{~mm}(100 \mathrm{~mm})$ over the peaks of the German Alps and the Black Forest mountains (not shown).

\subsection{Persistence analysis}

Days with widespread thunderstorms tend to form temporal clusters of variable length, which can be described statistically by the concept of persistence. In this study, a persistent cluster is defined as a sequence of days (between 1 
and 15 days) with the binary parameter taking the value of 1 (event day) or zero (non-event day). This is a familiar approach known from literature in its basic form (e.g. Wanner et al., 1997; Petrow et al., 2009). In order to facilitate the appropriate treatment of embedded days, on which the event does not occur (skip days), we refined the method by specifying that clusters with a length of up to 7 (15) days may contain at most 1 skip day ( 2 skip days). This step is necessary because the criteria for an event day might not be fulfilled on sporadic days, although convective predisposition clearly persists. Each time the algorithm identifies the end of a cluster according to these rules, the actual length, exclusive of skip days, is stored. The approach described is a top-down one: it considers only the maximum cluster length and prevents longer clusters from being split into two or more subclusters. Dividing the absolute number of clusters with length $n$ by the number of all clusters yields the relative frequency of a cluster with length $n$. Due to the large data volume, this can be perceived as an approximate measure for probability. Persistence analysis as described above is applied to precipitation severity index $\mathrm{PS}_{\xi}$ (Eq. 8), large-scale weather types, and compound events with low stability and weak flow.

\section{Weather situation}

Warm and moist air masses in combination with large-scale lifting by shallow surface lows persisted during STE16 over wide parts of Germany. Steep environmental lapse rates due to surface heating by solar radiation, cooling at mid and upper troposphere levels by cold air advection, and upper-level troughs created an environment favoring the development of various thunderstorms. Due to the very weak horizontal flow at mid-tropospheric levels - particularly in the second half of the period - the various thunderstorms were almost stationary, resulting in large precipitation accumulations over limited areas.

\subsection{Synoptic overview and atmospheric characteristics}

At the end of May and beginning of June, large parts of Europe were influenced by atmospheric blocking. Such a blocking event is characterized by large amplitude and long-lasting negative potential vorticity anomalies located beneath the dynamical tropopause (Croci-Maspoli et al., 2007). They establish most frequently over the North Atlantic and the northeastern Pacific during all four seasons but most frequently in autumn and winter. The usual westerly flow over Europe is blocked due to the presence of a high-pressure system over the North Atlantic or northern Europe. Such a block, termed as Omega-block in Europe, may persist over several days up to several weeks with enormous consequences for the regional weather and climate (Masato et al., 2013).

During STE16, the structure of the $500 \mathrm{hPa}$ mean geopotential height over Europe and the North Atlantic was char-

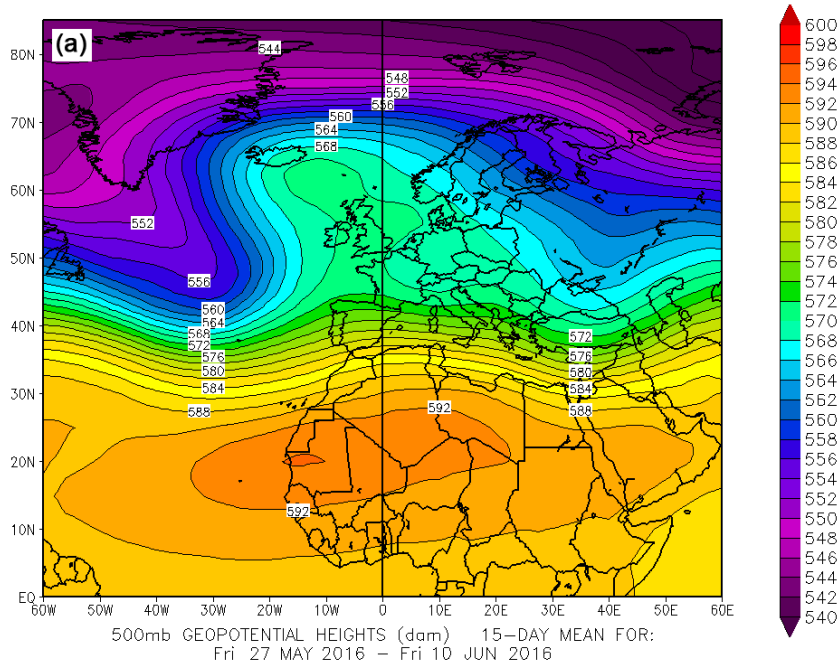

NCEP OPERATIONAL DATA SET

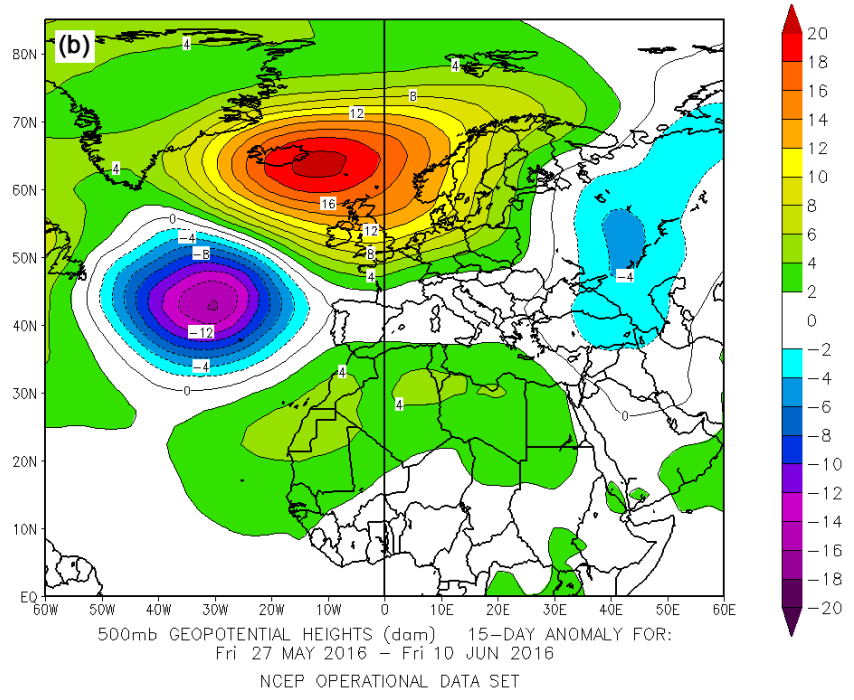

Figure 2. $500 \mathrm{hPa}$ geopotential height over Europe: (a) averaged between 27 May and 10 June 2016 and (b) departure from normal 1979-2005 (Image source: NOAA/ESRL Physical Sciences Division, Boulder Colorado, http://www.esrl.noaa.gov/psd).

acterized by a massive high-pressure system, which stretched from Great Britain to Iceland and central Scandinavia. The high-pressure block was flanked by two upper-level troughs (Fig. 2a). To the west a trough made its way southwards towards the Azores, whereas over eastern Europe another trough extended southwards to the Black Sea and Turkey.

The $500 \mathrm{hPa}$ geopotential anomalies with respect to the long-term mean (1979-2005) show some positive anomalies of around $20 \mathrm{hPa}$ occurring near Iceland, whereas negative anomalies of the same magnitude were present in the mid-Atlantic Ocean around the Azores (Fig. 2b). Unlike usual blocking situations, an area of low pressure was cut off beneath the northward bulging high-pressure ridge. Low $500 \mathrm{hPa}$ geopotential values could be identified over Poland, 
Germany, and France, accompanied by weak pressure gradients, resulting in low wind speeds at mid-tropospheric levels. The weak upper-level trough over central Europe corresponded with shallow surface lows, one of which extended between Poland and France and persisted until 9 June. Consequently, western and southern Germany remained under the influence of low pressure with moist and warm air, while drier air gradually prevailed in the northeast. At the beginning of the blocking event, moist and warm air was advected ahead of a deep trough northeastwards towards central Europe. Later in June, with the stationary low pressure being present across central Europe, moisture was maintained mainly by evapotranspiration from local sources and advection from nearby countries.

The most intense and fatal rain events occurred on 29 May over southwestern Germany. In the town of Braunsbach, for example, flash floods and landslides had devastating consequences (see Fig. 4a). During that day, the upper-level trough approached southern Germany from France and Switzerland. It was associated with massive positive vorticity advection and the advection of warm and moist air at lower and midtropospheric levels, which both reached their maximum values during the evening hours. Together, they provided a large uplift across western Bavaria and Baden-Württemberg. The preexisting air mass was unstably stratified, leading to negative SLI values of -5 and $-2 \mathrm{~K}$ in Munich and Stuttgart, respectively (Fig. 3).

The first thunderstorms on that day occurred over Bavaria already before noon. While the rain area extended towards western Baden-Württemberg, new and intense thunderstorms formed north of the Alps, followed by isolated heavy thunderstorms aligned from Munich to Salzburg and Nuremberg to Stuttgart. In the evening, a large mesoscale convective system (MCS) Type II, which usually develops from preexisting single cells, covered all of Baden-Württemberg, western Bavaria, eastern Rhineland-Palatinate, and southern Hesse with a size of roughly $60000 \mathrm{~km}^{2}$. At 19:00 UTC, a line of violent thunderstorms stretched over several hundred kilometers from Passau in eastern Bavaria to Mannheim in the northwestern tip of Baden-Württemberg. Various convective cells embedded in the eastern and northern edge of the MCS affected mainly the same region in the north of BadenWürttemberg, leading locally to rainfall totals in excess of $100 \mathrm{~mm}$ within a few hours (see Fig. 4a).

During the entire STE16 period, atmospheric stability across Germany (and central Europe) was low. The SLI computed at four sounding stations shows values below zero on almost every day (Fig. 3a, recall that negative SLI values express instability). SLI was particularly low at the beginning and in the second half of STE16. The values for $\mathrm{CAPE}_{100 \mathrm{hPa}}$, which is calculated based on start values of the lifted curve being mixed over the lowest $100 \mathrm{hPa}$, were above $400 \mathrm{~J} \mathrm{~kg}^{-1}$ on most days, with maximum values between 800 and $1100 \mathrm{~J} \mathrm{~kg}^{-1}$.
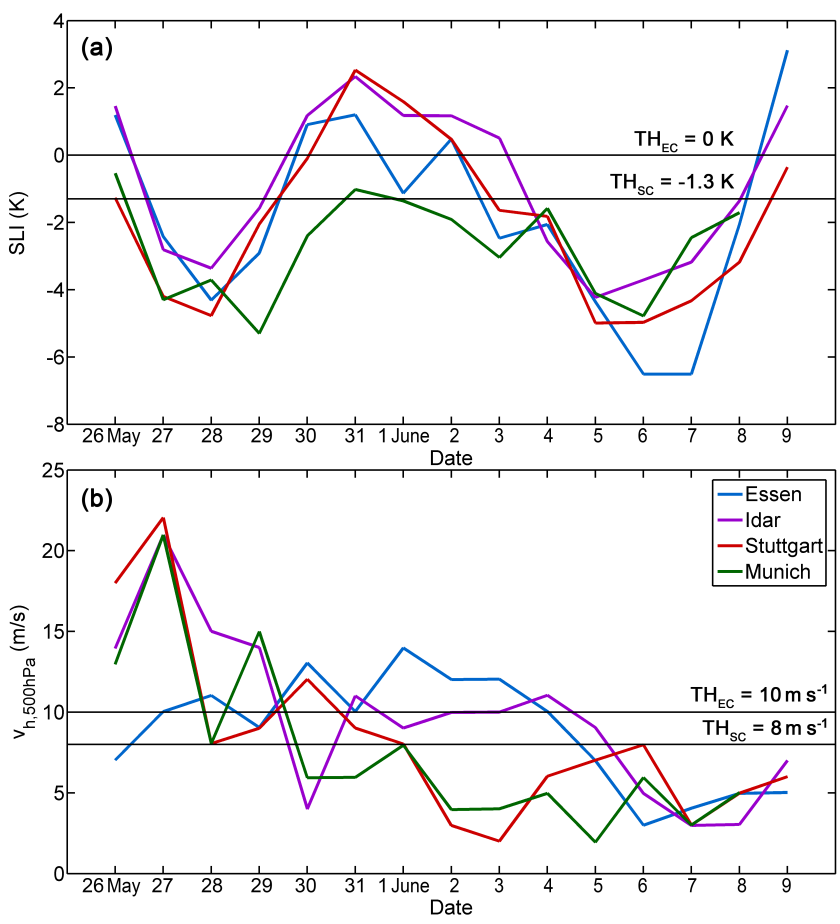

Figure 3. Time series of (a) surface lifted index (SLI) and (b) horizontal wind speed in $500 \mathrm{hPa}\left(v_{\mathrm{H}, 500 \mathrm{hPa}}\right)$ at 12:00 UTC at four German sounding stations during STE16, including the thresholds (TH) defined in Sect. 4.3.

Apart from the first 2 days, wind speed at $500 \mathrm{hPa}$ was exceptionally low, with values between only 2 and $15 \mathrm{~m} \mathrm{~s}^{-1}$ (Fig. 3b). Especially at the two stations located in southern Germany, Stuttgart and Munich, where most of the flash floods occurred, the values dropped below $10 \mathrm{~m} \mathrm{~s}^{-1}$ on 31 May and remained on a very low level until the end of STE16. Only the two stations situated in the center of Germany showed wind speeds of around $10 \mathrm{~m} \mathrm{~s}^{-1}$ or slightly above. The general wind direction at $500 \mathrm{hPa}$, until $28 \mathrm{May}$, was predominantly from the west at all four stations considered. Afterwards, the flow turned to southerly (29-30 May) and mainly easterly directions that prevailed until 6 June. The last 3 days were again dominated by westerly flow. Note, however, that wind directions during calm winds have a very limited applicability.

According to DWD analysis (DWD, 2016), the OWLK pattern that prevailed on the first 3 days (26 to 28 May) was SWCCM, indicating moist southwesterly flow with cyclonic rotation at both levels (Table 1). Several studies identified this pattern to be most related to severe thunderstorm occurrence in Germany (Kapsch et al., 2012; Mohr et al., 2015). After the first 3 days, flow direction became mainly indefinite $(\mathrm{XX})$ due to the very weak winds connected to the low pressure gradients. On all days, atmospheric moisture was increased, yielding the weather types XXAAM and XXCCM. These two types have been found to promote thunderstorms 

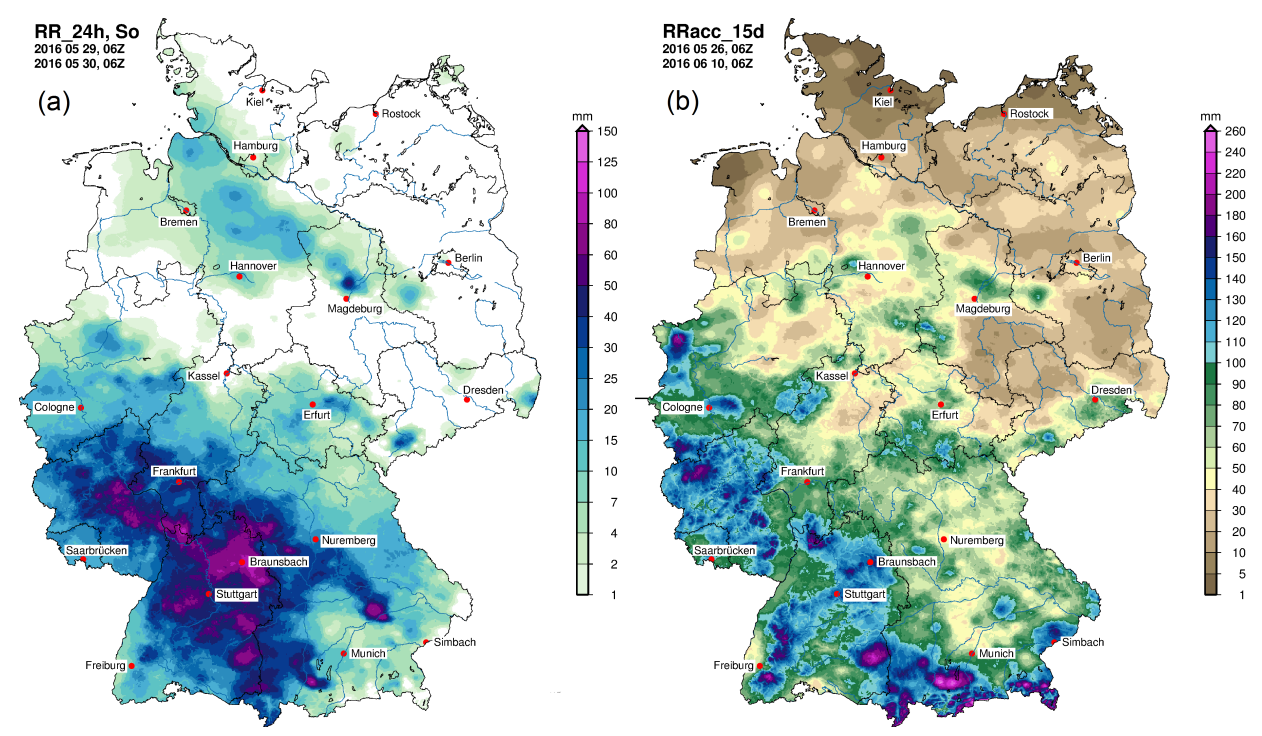

Figure 4. Gridded rain totals (REGNIE) over (a) $24 \mathrm{~h}$ for 29 May 2016 and (b) 15 days (26 May to 9 June 2016, STE16).

as well, for example with a probability of $10 \%$ for damaging hail (Kapsch et al., 2012).

As discussed in Sect. 2.4, the original OWLK was not designed especially for the analysis of convective conditions. Therefore, we developed a new classification (conOWLK) optimized in this regard. According to conOWLK and using CFSv2 reanalysis data (Sect. 2.2.2), 6 days can be classified as convection favoring (WMIL or WMIX). These two weather types are characterized by near-zero false alarm rates but with a considerable number of missed events with respect to the occurrence of convective days (not shown). This feature is equivalent to the statement that a categorization as WMIL or WMIX is by approximation sufficient, but not necessary for the actual incidence of lightning. Due to the strict design of conOWLK, WMIL and WMIX coincide with a very high probability for the development of severe thunderstorms. Thus, the number of 6 out of 15 days exhibiting one of these weather types has to be considered as fairly high.

\subsection{Precipitation}

The majority of thunderstorms that developed during STE16 showed a typical diurnal cycle peaking in the afternoon and early evening. On most of the days, intense rainfall affected only small areas, with extensions of only a few square kilometers. According to radar data, the diameters of the cloud bursts were in the order of several hundreds of meters to 1 or $2 \mathrm{~km}$.

\subsubsection{Rainfall totals}

Thunderstorms with at least $50 \mathrm{~mm}$ rainfall totals within $24 \mathrm{~h}$ occurred on 11 days during STE16 (Table 2). Most of the rain fell within only a few hours. As shown in Table 2 for se- lected rain gauges, the Wussow criterion (Eq. 7) was met at seven of the eight chosen stations, for which hourly data are available. The largest rain amount during this period was observed at Gundelsheim ( $\sim 50 \mathrm{~km}$ west of Braunsbach) with $122.1 \mathrm{~mm}$ on 29 May 2016. On this day, heavy rainfall associated with the large MCS caused widespread totals in excess of $50 \mathrm{~mm}$ (see also Fig. 4a). Around Simbach in Bavaria, a maximum of $74.6 \mathrm{~mm}$ was recorded on 31 May, triggering another devastating flood. Unfortunately, the rain gauge had a malfunction on 1 June for $4 \mathrm{~h}$. Filling up the gap with DWD radar data gives a daily total of about $120 \mathrm{~mm}$ on this day, which may be even higher than the given value in Table 2. Hence, Simbach would be the only station with a Germanywide maximum on 2 days during STE16.

Accumulated 15-day rain totals in Germany widely exceeded a height of $100 \mathrm{~mm}$ (Fig. 4b). In several parts of Baden-Württemberg and Bavaria even more than $250 \mathrm{~mm}$ was observed, which is far more than the climatological mean for the entire month of June. Dry conditions prevailed only towards the North Sea and Baltic Sea region as well as in most parts of Brandenburg, where values rarely exceeded $40 \mathrm{~mm}$.

\subsubsection{Return periods}

Return periods estimated with respect to $\mathrm{C} 20 / 21$ allow for assessing the observed totals in the historic context. Based on Eq. (6), we determined return periods for each day and each grid point during STE16 based on REGNIE $24 \mathrm{~h}$ totals. Additionally, we quantified 7-day return periods shifted by 1 day during STE16, yielding nine 7-day subintervals.. Afterwards, we identified the highest return period at each grid point, both for $24 \mathrm{~h}$ and 7 -day totals. These results together 

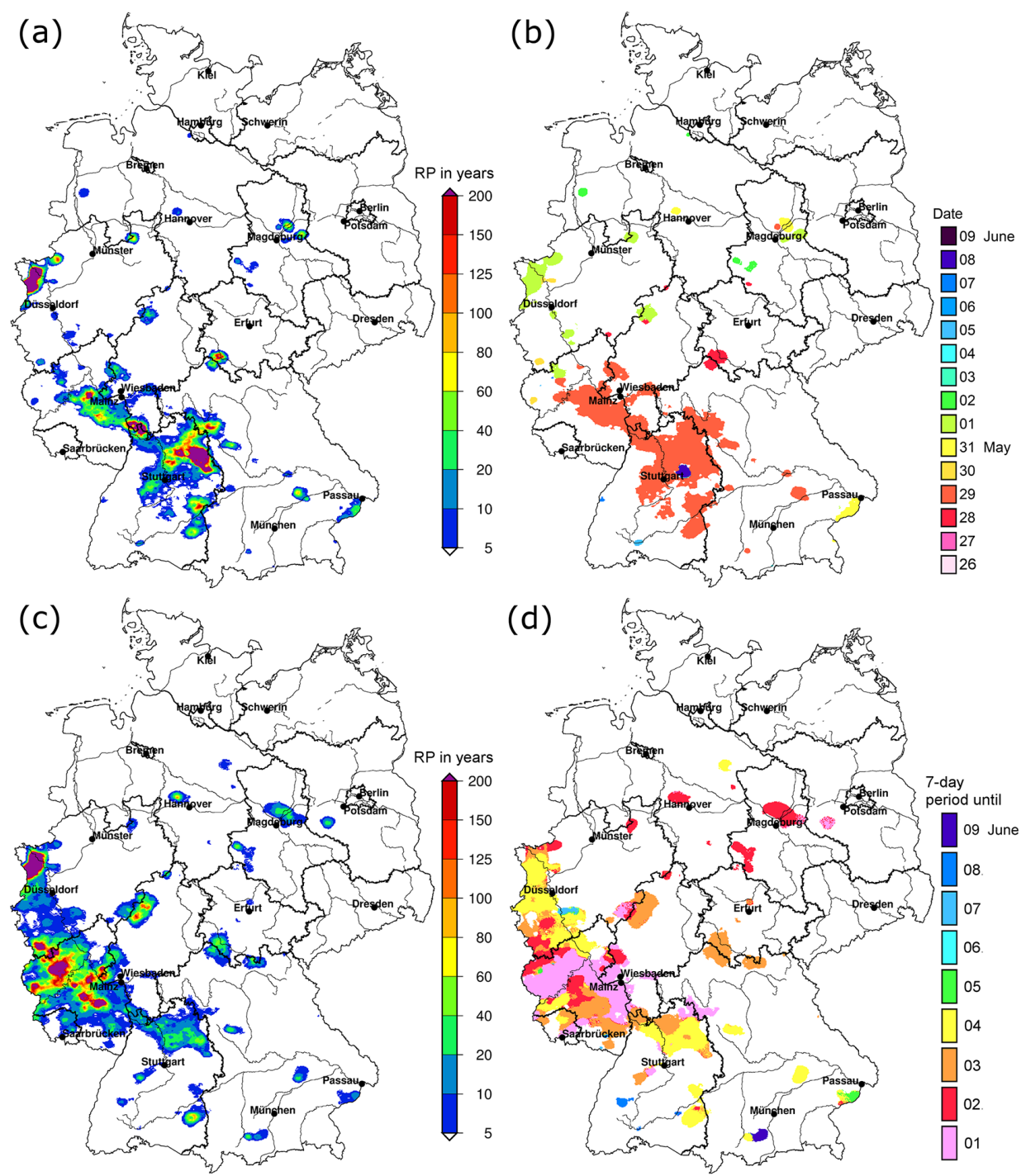

Figure 5. Spatial distribution of maximum return periods of (a) $24 \mathrm{~h}$ and (c) 7-day totals and (b,d) the day of occurrence during STE16 derived from REGNIE data; return periods are estimated with respect to the control period C20/21 (SHY).

with the days and time intervals of maximum return periods are shown in Fig. 5.

Daily totals reveal widespread return periods larger than 40 years but with several hot spots of more than 200 years, especially around Braunsbach and the far west of Germany (Fig. 5a). The temporal distribution (Fig. 5b) shows that 29 May, and to a lesser degree 1 June, represent the dominant days for these totals. Minor return periods between 40 and 60 years occurred in the Simbach area, which can be explained by the malfunction of the most important rain gauge in that area on 1 June.

As shown in Table 2, most of the observed daily maxima recorded at selected rain gauges had return periods of at least 5 years, with the two outstanding events of 29 May (Gundelsheim) and 1 June (Hamminkeln-Mühlenrott) exhibiting values of more than 200 years. The reconstructed data at
Simbach on 1 June would yield high return periods of about 140 years as well.

Considering the 7-day totals, a westward shift of the affected area is obvious. Emphasis now is on RhinelandPalatinate west of Frankfurt (Fig. 5c), again with enclosed areas of very high return periods including the upper catchment of the river Ahr (along the border between RhinelandPalatinate and North Rhine-Westphalia). The majority of the maximum return periods occurred during the first 7-day period from 26 May to 1 June (Fig. 5d, pink), leading to the most serious flood along the river Ahr ever reported. Note that $24 \mathrm{~h}$ totals in some regions were so exceptionally high that they also massively affected the 7-day totals and corresponding return periods.

Comparing the spatial distributions of $24 \mathrm{~h}$ and 7-day return periods (and additionally of 3-day and 14-day periods, 
Table 2. Maximum observed $24 \mathrm{~h}$ totals $R_{24} \mathrm{~h}$ (in $\mathrm{mm}$ ) at any rain gauge of DWD (name and coordinates) for each day in STE16 and beginning of the record and corresponding return period $t_{\mathrm{RP}}$ (in years). Different durations $D$ are shown (if available) together with the related heavy rainfall criterion $N_{\mathrm{cr}}$ (in $\mathrm{mm}$ ).

\begin{tabular}{|c|c|c|c|c|c|c|}
\hline Date & Station [coordinates] & Data since & $R_{24 \mathrm{~h}}$ & $t_{\mathrm{RP}}$ & Duration $D$ & $N_{\mathrm{cr}}$ \\
\hline 26 May & Bitburg $\left[49.98^{\circ} \mathrm{N}, 6.53^{\circ} \mathrm{E}\right]$ & 1951 & 37.8 & $<5$ & in $10 \mathrm{~h}(28.3 \mathrm{~mm}$ in $6 \mathrm{~h})$ & $54.8(42.4)$ \\
\hline 27 May & Eppendorf $\left[50.80^{\circ} \mathrm{N}, 13.24^{\circ} \mathrm{E}\right]$ & 1951 & 47.4 & $<5$ & & \\
\hline 28 May & Siegen (Kläranlage) $\left[50.85^{\circ} \mathrm{N}, 8.00^{\circ} \mathrm{E}\right]$ & 1931 & 59.0 & $10-15$ & in $4 \mathrm{~h}$ & 34.6 \\
\hline 29 May & Gundelsheim $\left[49.28^{\circ} \mathrm{N}, 9.16^{\circ} \mathrm{E}\right]$ & 1888 & 122.1 & $>200$ & & \\
\hline 30 May & Kall-Sistig $\left[50.50^{\circ} \mathrm{N}, 6.52^{\circ} \mathrm{E}\right]$ & 1947 & 63.5 & $20-25$ & in $13 \mathrm{~h}(53.2 \mathrm{~mm}$ in $5 \mathrm{~h})$ & $62.4(38.7)$ \\
\hline 31 May & Simbach/Inn $\left[48.27^{\circ} \mathrm{N}, 13.02^{\circ} \mathrm{E}\right]$ & 1951 & 74.6 & $5-10$ & $42.8 \mathrm{~mm}$ in $6 \mathrm{~h}$ & 42.4 \\
\hline 1 June* & $\begin{array}{l}\text { Hamminkeln-Mühlenrott } \\
{\left[51.72^{\circ} \mathrm{N}, 6.58^{\circ} \mathrm{E}\right]}\end{array}$ & 1931 & 120.3 & $>200$ & & \\
\hline 2 June & Wernigerode $\left[51.84^{\circ} \mathrm{N}, 10.77^{\circ} \mathrm{E}\right]$ & 1951 & 61.0 & $10-15$ & $60.9 \mathrm{~mm}$ in $5 \mathrm{~h}$ & 38.7 \\
\hline 3 June & Hohenpeißenberg $\left[47.80^{\circ} \mathrm{N}, 11.01^{\circ} \mathrm{E}\right]$ & 1801 & 61.3 & $5-10$ & in $6 \mathrm{~h}$ & 42.4 \\
\hline 4 June & $\begin{array}{l}\text { Lenggries (Sylvenstein) } \\
{\left[47.69^{\circ} \mathrm{N}, 11.57^{\circ} \mathrm{E}\right]}\end{array}$ & 1931 & 87.5 & $5-10$ & & \\
\hline 5 June & Karsdorf $\left[50.94^{\circ} \mathrm{N}, 13.70^{\circ} \mathrm{E}\right]$ & 1978 & 65.7 & $5-10$ & & \\
\hline 6 June & $\begin{array}{l}\text { Frankenblick-Mengersgereuth-Hämmern } \\
{\left[50.39^{\circ} \mathrm{N}, 11.13^{\circ} \mathrm{E}\right]}\end{array}$ & 1969 & 44.5 & $<5$ & $44.1 \mathrm{~mm}$ in $1 \mathrm{~h}$ & 17.3 \\
\hline 7 June & Durbach-Ebersweier $\left[48.50^{\circ} \mathrm{N}, 7.99^{\circ} \mathrm{E}\right]$ & 1951 & 62.3 & $10-15$ & in $4 \mathrm{~h}(52.0 \mathrm{~mm}$ in $1 \mathrm{~h})$ & $34.6(17.3)$ \\
\hline 8 June & Fellbach $\left[48.81^{\circ} \mathrm{N}, 9.27^{\circ} \mathrm{E}\right]$ & 1941 & 67.8 & $25-30$ & & \\
\hline 9 June & $\begin{array}{l}\text { Neureichenau-Duschlberg } \\
{\left[48.79^{\circ} \mathrm{N}, 13.73^{\circ} \mathrm{E}\right]}\end{array}$ & 1931 & 38.7 & $<5$ & & \\
\hline
\end{tabular}

* Malfunction at Simbach am Inn on 1 June 2016 08:00-11:00 UTC. Complementation with data of the corresponding grid point of radar data yields approximately $R_{24 \mathrm{~h}} \approx 120 \mathrm{~mm}(\approx 90 \mathrm{~mm}$ in $6 \mathrm{~h})$ and a return period $t_{\mathrm{RP}}$ of $135-140$ years; heavy rain criterion $N_{\mathrm{cr}}$ for $24 \mathrm{~h}(6 \mathrm{~h})$ totals: $84.5 \mathrm{~mm}(42.4 \mathrm{~mm})$, fulfilled in both cases.

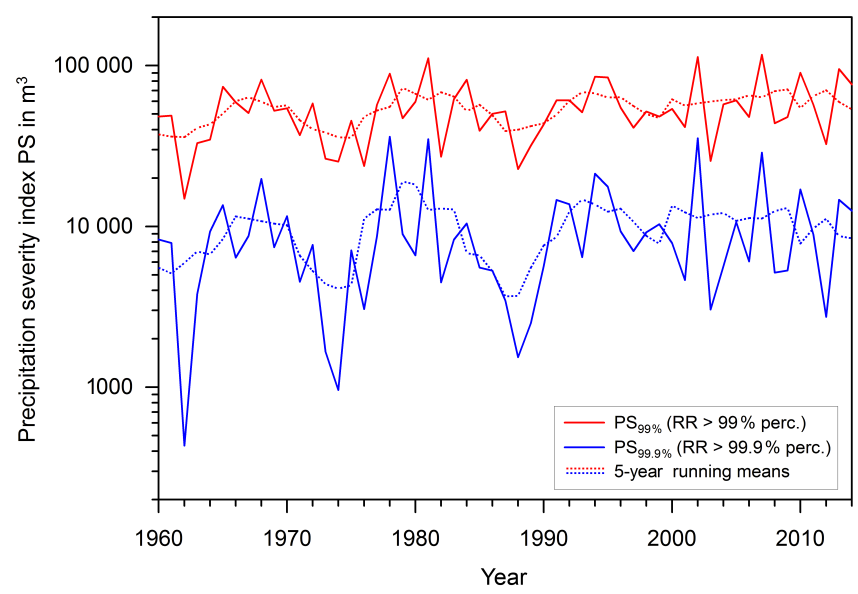

Figure 6. Time series of the annually accumulated precipitation severity index $\mathrm{PS}_{\xi}$ for all REGNIE grid points of the investigation area including 5-year running mean during C20/21.

which are not shown), it can be concluded that in most regions heavy precipitation occurred just on 1 or 2 days during STE16 (e.g., Braunsbach or Simbach). Only a few regions such as Rhineland-Palatinate, especially the upper Ahr catchment, experienced rainfall on more than 2 days. This fact is a typical feature of heavy convective rainfall, which was more or less randomly spread over large parts of Germany during STE16.

\section{Persistence analysis}

Aside from exceptional rainfall totals with return periods in excess of 200 years, another peculiarity of STE16 was the almost daily occurrence of severe thunderstorms somewhere in the investigation area. For this reason, we investigate how often persistent clusters of days with convective weather conditions occur in the long-term mean (C20/21) in terms of heavy rain events based on the precipitation severity index $\mathrm{PS}_{\xi}$ (Sect. 4.1), large-scale weather patterns (Sect. 4.2), and compound events with low stability and weak flow (Sect. 4.3).

\subsection{Heavy rainfall}

The time series of the annually accumulated precipitation severity index $\mathrm{PS}_{\xi}^{k}$ (Eq. 8) for the two percentiles 99 and $99.9 \%$ based on REGNIE totals are qualitatively similar (Fig. 6). In both cases, the temporal variability is high, with values in a range between 14865 and 116983 for $\mathrm{PS}_{99}$ and between 432 and 36125 for PS99.9. An interesting feature is the long-term oscillation inherent in both time series, but it is more pronounced in the case of the convection-dominated $\mathrm{PS}_{99.9}$ index. The FFT (fast Fourier transform) power spectrum (removal of linear trend) reveals the highest peaks for a periodicity between 2 and 3 years as well as a large peak for 13 years (not shown). Possible reasons for these oscillations remain unclear since a direct link to weather patterns or stability cannot be established. The two time series in Fig. 6 


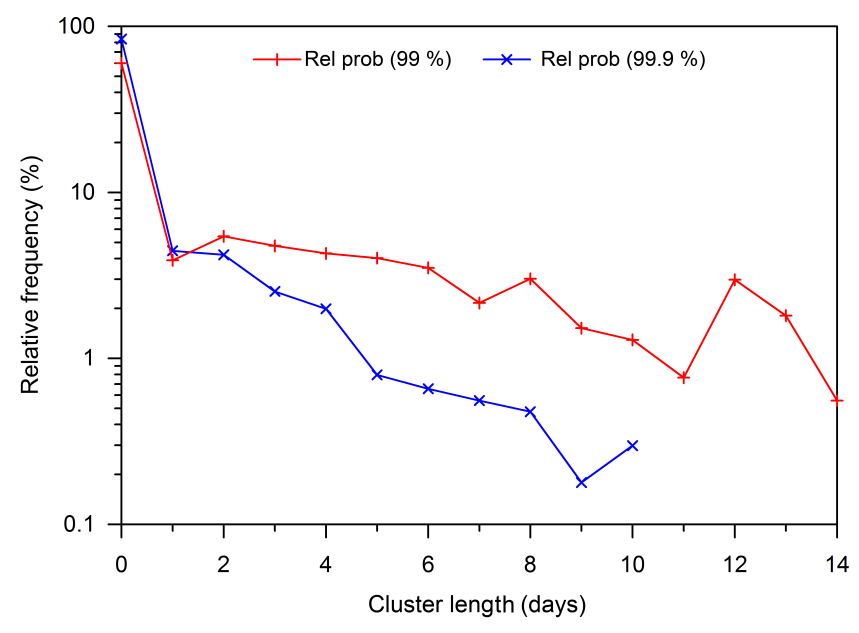

Figure 7. Relative frequency of clusters of consecutive days exceeding the threshold of $\mathrm{PS}_{\xi}$ for the 99 and $99.9 \%$ percentiles during C20/21.

also show positive (linear) trends, which, however, are statistically insignificant $(\alpha>5 \%)$ due to the large volatility.

During STE16, PS $_{99.9}>0$ at any location (REGNIE grid point) in the investigation area occurred on 10 consecutive days, whereas $\mathrm{PS}_{99}>0$ was reached on 14 days. To assess the exceptional nature of this persistence, we estimated the occurrence probability of clusters with a length between 2 and 15 extreme rainfall days during C20/21 (see Sect. 2.7). Extreme rainfall days are defined when $\mathrm{PS}_{\xi}>0$ at any location across the investigation area, which best represents the spatial characteristics of STE16 with spatially varying hot spots of heavy rainfall.

According to Fig. 7, the occurrence probability of a 14-day cluster with $\mathrm{PS}_{99}>0$ is $0.56 \%$. Aside from the year of 2016 , this cluster occurred only four times during C20/21 (1970, 1997, 2000, and 2006). For PS $99.9>0$, the maximum cluster had a length of 10 days, and occurred three times in C20/21 (1963, 1972, and 2002; see Fig. 8). Thus, the probability of such a cluster is even lower with a value of $0.30 \%$.

Figure 7 also shows that on most of the days, $\mathrm{PS}_{\xi}$ is not exceeded in the entire investigation area $(60.0 \%$ of all days for the 99 , and $83.9 \%$ for the $99.9 \%$ percentile). As expected, the relative frequency of occurrence substantially decreases with increasing cluster length, with some exceptions. For example for $\mathrm{PS}_{99.9}$, a cluster length with 10 days has a higher probability than a cluster of only 9 days $(0.3 \%$ vs. $0.18 \%$, or two vs. three events, respectively). This apparently counterintuitive behavior can also be observed in the probabilities of the clusters for the weather types and the compound low stability and weak flow events (see Figs. 9 and 12). In both cases, however, the changes affect different cluster lengths. The reason for this behavior remains unclear, but might be the consequence of the large natural variability of convective weather as already indicated by the large volatility of $\mathrm{PS}_{\xi}$.

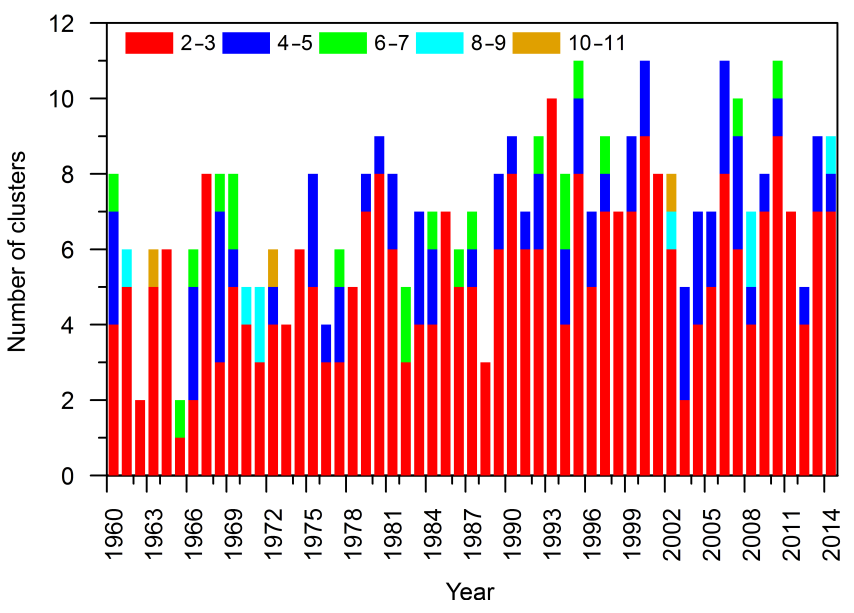

Figure 8. Time series of different cluster lengths with respect to consecutive days exceeding the threshold of $\mathrm{PS}_{99.9}$ during C20/21.

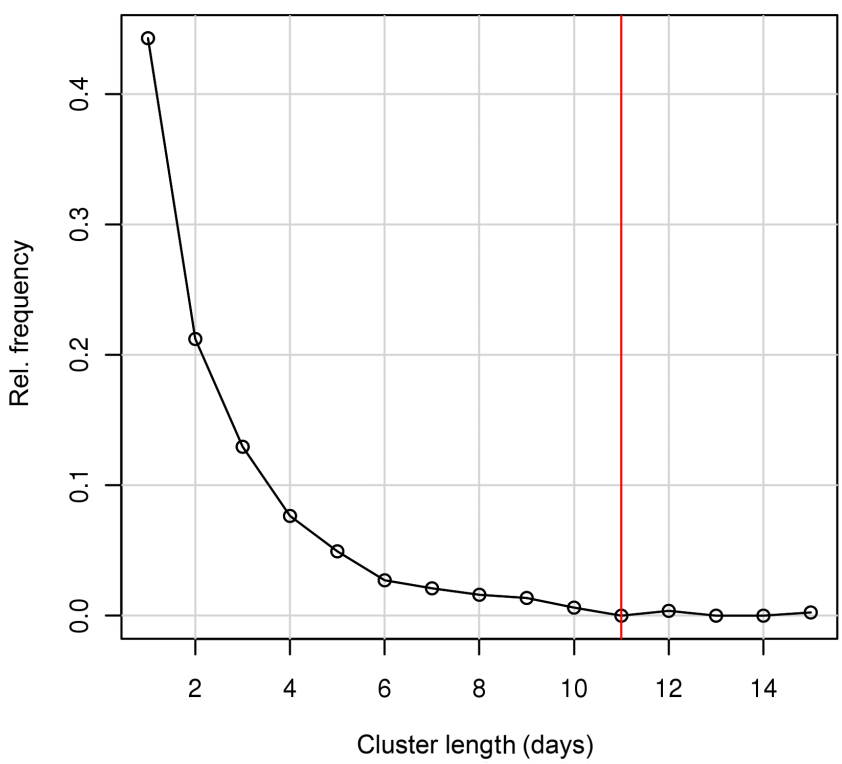

Figure 9. Same as Fig. 7, but for days classified as convective according to quadratic discriminant analysis; red: cluster length observed during STE16.

The time series of the different clusters do not reveal any systematics; rather, their occurrence has a large stochastic component (Fig. 8). However, whereas the number of shorter clusters (2-5 days) increased during C20/21, the number of larger clusters ( $>5$ days) decreased slightly. The lower number of larger clusters cannot compensate for the increase of shorter clusters, leading to an overall positive trend. However, due to the large annual variability and the small number of clusters, a robust statement about an increase or decrease cannot be derived from this analysis. 


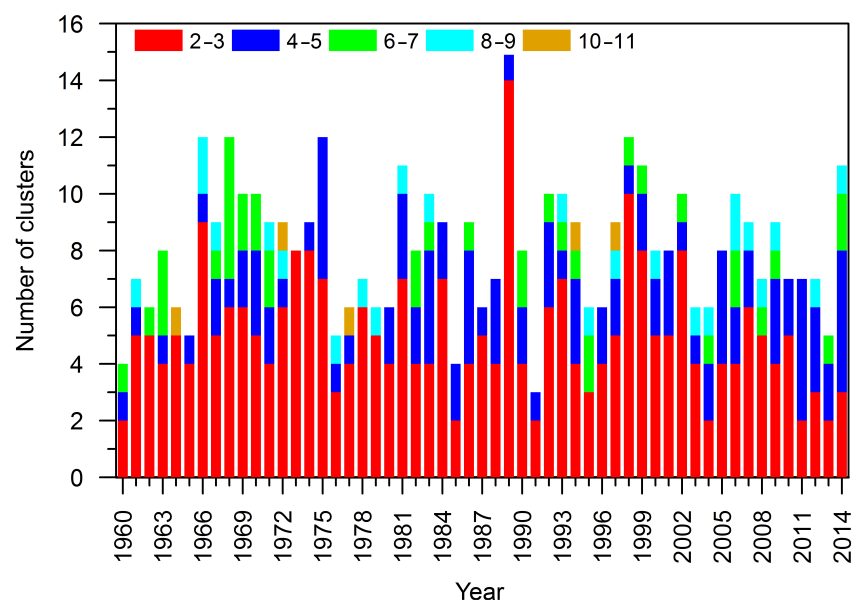

Figure 10. Same as Fig. 8, but with respect to consecutive days classified as convective according to quadratic discriminant analysis during C20/21.

\subsection{Large-scale weather types}

Considering the original OWLK provided by DWD, a cluster length of 8 days ( 1 skip day) regarding the weather types XX..M (where . denotes either cyclonic (C) or anticyclonic (A) vorticity in each case) was observed during STE16 (see Table 1). Adding the first 3 days exhibiting the weather type SWCCM, which has been shown to favor thunderstorm formation as well (Sect. 3.1), even yields an 11-day cluster (2 skip days). Both lengths have never occurred before since the beginning of the OWLK record in 1979.

The total of 6 convective days according to conOWLK in the investigation area subdivide into three clusters of lengths: 3, 2, and 1 days on 28-29 May and 3-5 and 8 June, respectively (Table 1). It is interesting to note that these clusters are separated by several days assigned to the group of neutral weather types. This finding can be attributed to the concept of combining single trichotomous parameters. Recall that conOWLK classifies a day as neutral or convectioninhibiting if just one of the parameters is slightly below the considered threshold, whereas the other three parameters may be well above.

As already discussed in Sect. 3.1, only days with a very high probability for strong convective development will be classified as convection favoring concerning all four parameters. Except for the first and last day, when the convective situation was not fully developed, all days were categorized as warm, and all but 2 days were assigned to the moist and unstable class. In contrast, 6 days with large-scale subsidence $(w<0)$ were detected. Consequently, neglecting the lifting parameter $w$ would yield two clusters of 4 days and one cluster of only 1 day. Since STE16 was characterized by spatially varying hot spots of severe convective activity, it can be assumed that convection was mainly triggered by mesoscale flow convergence in the boundary layer instead of large-scale lifting, except for the large MCS on 29 May. Thus, strong local vertical velocity maxima may be overcompensated for by subsidence in other regions.

These findings suggest that conOWLK is too strict when persistence analysis with respect to the presence of a high convective predisposition is attempted instead of focusing on days characterized by very high probabilities of strong thunderstorm events only. Therefore, another type of classification abbreviated as qdaOWLK is used, which does not rely on a simple combination of parameters exceeding the respective thresholds. Quadratic discriminant analysis, as introduced in Sect. 2.4, provides a suitable statistical model that is based on the parameter values calculated by the conOWLK algorithm as well, but it leaves out mapping these parameters on categorical variables. Cross-validation with respect to the occurrence of convective days yields a HSS of 0.53 . According to this model and using CFSv2 data, a cluster length of 11 convective days was detected during STE16 (2 skip days).

As for the precipitation severity index $\mathrm{PS}_{\xi}$, we also estimate the empirical relative frequency distribution of different cluster lengths with respect to qdaOWLK. For this purpose, a time series of the binary variable convective day was computed for $\mathrm{C} 20 / 21$ using the discriminant model. As shown in Fig. 9, two thirds of all clusters exhibit a length of 1 or 2 days. Cluster durations of more than 15 days have not yet occurred since the beginning of the reference period. Less than $1 \%$ of all cluster lengths exceed 10 days. Consequently, the 11-day cluster of convective days has to be considered as highly exceptional. Due to the sample size of 811 clusters, the relative frequencies obtained can be interpreted by approximation as probabilities.

All cluster lengths exhibit a strong interannual variability (Fig. 10), which is characterized by a large stochastic component, as was the case regarding days with heavy rainfall (Fig. 8). In some years, we observe remarkable extrema, for example in 1989, when 14 clusters with a length of 2-3 days and only one cluster of 4-5 days occurred. Conversely, 1991 was generally characterized by weak convective activity $(2$ clusters with 2-3 days and 1 cluster with 4-5 days). A 1011-day cluster occurred only five times (1964, 1972, 1977, 1994, 1997). In contrast to the time series of heavy rainfall clusters, no long-term increases or decreases are visible.

\subsection{Compound events with low stability and weak flow}

In the last step, we investigate compound events with low stability and weak flow prevailing during STE16 with the same methods as applied above. The following two threshold combinations based on surface lifted index (SLI) and horizontal wind speed in $500 \mathrm{hPa}\left(v_{\mathrm{H}, 500 \mathrm{hPa}}\right)$ are considered in the analysis:

1. Basic criterion $(\mathrm{BC})$ : $\mathrm{SLI}<0 \mathrm{~K}$ and $v_{\mathrm{H}, 500 \mathrm{hPa}}<10 \mathrm{~m} \mathrm{~s}^{-1}$, 


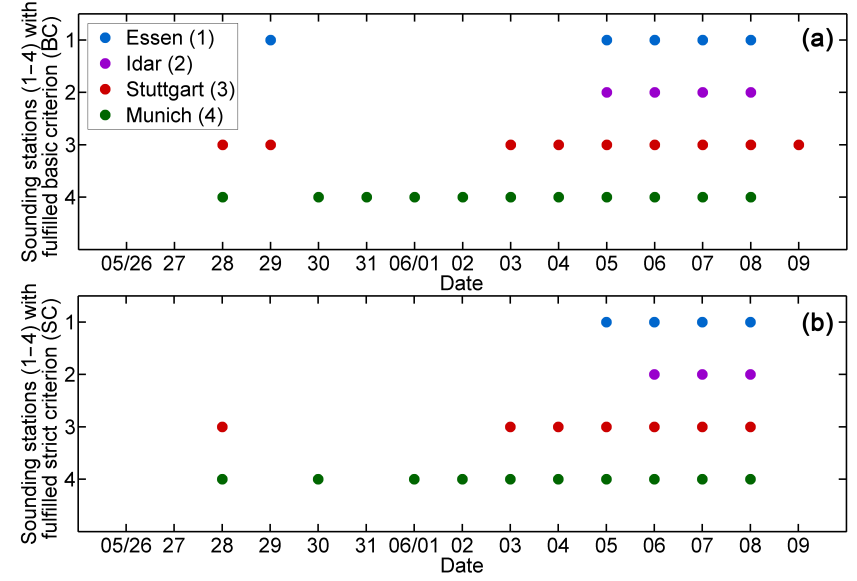

Figure 11. Time series of compound low stability and weak flow events at 12:00 UTC during STE16 at four German sounding stations for days, on which (a) the basic (BC) and (b) the strict criteria (SC) are fulfilled (represented by the dots).

\section{Strict criterion (SC):}

$$
\mathrm{SLI}<-1.3 \mathrm{~K} \text { and } v_{\mathrm{H}, 500 \mathrm{hPa}}<8 \mathrm{~m} \mathrm{~s}^{-1} \text {. }
$$

The thresholds representing the $\mathrm{BC}$ are defined by the maximum of the daily minima at all four sounding stations during STE16 (see Fig. 3), representing the prevailing atmospheric conditions during STE16 in the investigation area. In that period, the $\mathrm{BC}$ criterion was fulfilled on 13 days (sounding stations Stuttgart and/or Munich, see Fig. 11a). The SC is defined in the same way as BC, but neglecting the day with the highest values; it was fulfilled at the Munich station with a cluster length of 10 days (2 skip days, see Fig. 11b)

Based on sounding measurements and reanalysis data (CoastDat2), we investigated the frequency of varying cluster lengths for both criteria (BC-SC) during C20/21. According to Fig. 12, the relative frequency of cluster lengths greater than or equal to 13 days (BC) or 10 days (SC) is very low $(<1 \%)$. This applies to both the analysis based on the Stuttgart sounding as well as to that considering $(3 \times 3)$ grid point averages from CoastDat2 near Stuttgart and $\mathrm{Mu}-$ nich. Regarding wind speed $v_{\mathrm{H}, 500 \mathrm{hPa}}$ solely, an almost identical behavior is found. It has to be noted that longer cluster lengths for BC-SC combinations based on sounding data occur less frequently compared to those based on model data, which means that those events are probably overestimated in CoastDat2.

The climatological distributions of the BC-SC combinations show a distinct north-to-south gradient (not shown). Therefore, regions in the south of Germany show a higher frequency of both the mean distribution of days with compound low stability and weak flow and events with longer cluster lengths (cf. Stuttgart vs. Munich in Fig. 12). This fact can be explained by the lower stability in southern Germany in the mean (Mohr and Kunz, 2013).
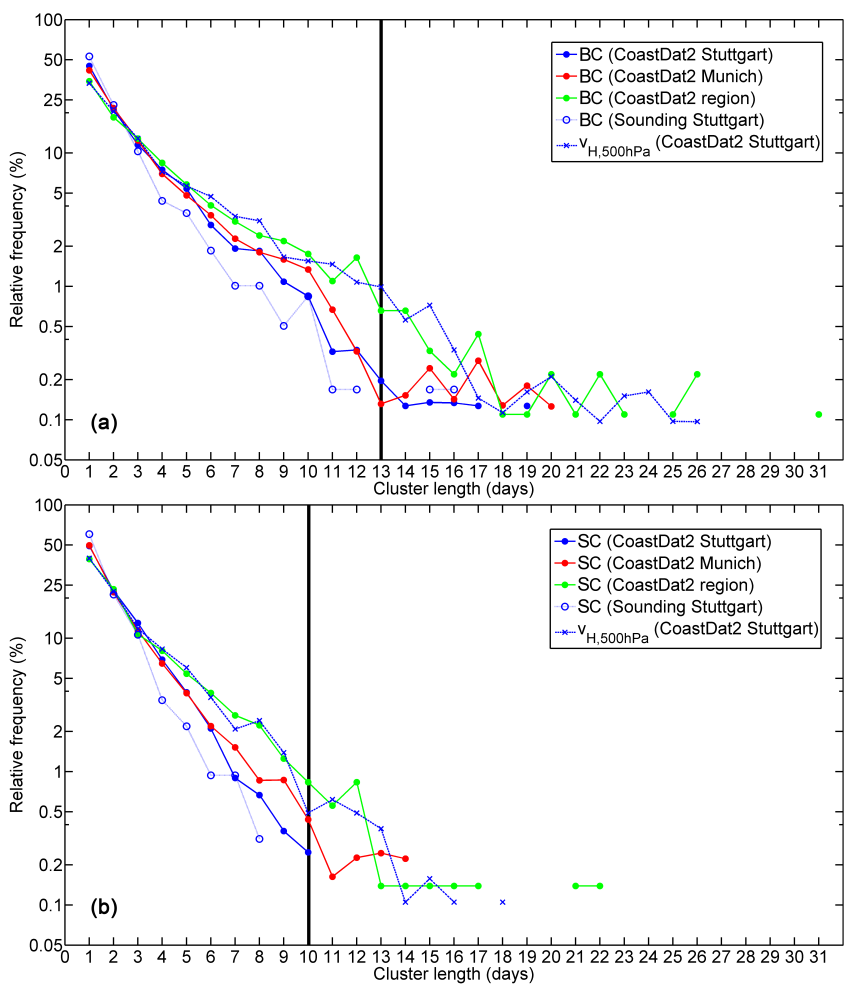

Figure 12. Same as Fig. 7, but for days fulfilling the (a) BC and (b) SC criteria for compound events with low stability and weak flow at the sounding station of Stuttgart (blue dotted line), $3 \times 3$ grid point averages near Stuttgart (blue solid line) and Munich (red solid line), and for days with a certain spatial extent $\left(A_{\mathrm{c}}\right.$, green solid line). Clusters for wind speed near Stuttgart according to the BC-SC criteria are also indicated (light dotted line). Cluster lengths during STE16 are marked as black vertical lines. See text for further details.

Finally, we examined the spatial extent of the SLI-wind combinations in the investigation area. In the first step, we identified the area that fulfilled the BC-SC combinations on each day during STE16 based on CFSv2 analysis. Accordingly, both criteria were reached in an area of at least $A_{\mathrm{c}}=$ $14 \times 10^{4} \mathrm{~km}^{2}$. This value is considered as a lower threshold for the convective area. In the second step, now based on CoastDat2, we checked for each day during C20/21 whether the BC-SC combination was fulfilled over an area of at least $A_{\mathrm{c}}$ or not. The persistence analysis of that time series is also shown in Fig. 12. For both BC-SC combinations, the relative frequency is higher compared to the persistence without considering the spatial extent (Stuttgart and Munich). For example, the probability of a cluster length greater than or equal to 13 or 10 days is between 3.0 and $3.5 \%$ for $\mathrm{BC}$ and $\mathrm{SC}$. Finally, we identified the total area with $2.7 \times 10^{6} \mathrm{~km}^{2}$, where these compound events (according to the $\mathrm{BC}$ criterion) prevailed during the 13 days in STE16. This affected area was unique until now and was never reached in C20/21, where 
the area was normally between 0.8 and $1.9 \times 10^{6} \mathrm{~km}^{2}$ for the same (or even higher) cluster length.

\section{Conclusions}

The severe thunderstorm episode in May-June 2016 in Germany (STE16) was investigated with respect to rain intensity and the presence of convection-favoring conditions in comparison to a 55-year control period C20/21 (1960-2014). For the latter, we considered different proxies such as convective parameters obtained from soundings and large-scale weather patterns computed from reanalysis data. We estimated empirical probability distributions with respect to variable cluster lengths of consecutive days with convective weather situations based on the different proxies.

The results illustrate that the interaction of convectionfavoring weather patterns, low thermal stability, and weak wind speed provided important boundary conditions for the extraordinary thunderstorm anomaly observed. Due to atmospheric blocking, these conditions persisted over almost 2 weeks. The low wind speed at mid-tropospheric levels ensured that convective cells were almost stationary, leading to locally extreme rain accumulations of more than $100 \mathrm{~mm}$, yielding return periods in excess of 200 years for both $24 \mathrm{~h}$ and 7-day totals.

From the persistence analysis it can be concluded that the number of days with prevailing extreme precipitation or convection-favoring conditions during STE16 was extraordinary, but not unique. This conclusion, however, depends on the proxy considered. For the precipitation severity index PS based on the $99.9 \%$ percentiles, for example, it was found that a 10-day cluster as observed during STE16 has a probability of only $0.3 \%$. Compound events with low stability and weak mid-troposphere flow estimated from soundings are rare, but they occurred several times during C20/21. A cluster with a length of 13 days for these conditions, for example, has a probability between 0.1 and $0.2 \%$ in southern Germany. The total area affected during 13 days, where these compound events prevailed, however, was unique in 2016 and has never occurred to that extent during the last half century.

Large-scale weather patterns dominating STE16 can be best described by both the objective weather-type classification OWLK and two specific convection-based classification schemes. A cluster length of 8 days exhibiting the OWLK type XX..M (where .. denote either a cyclonic or anticyclonic circulation pattern in 950 or $500 \mathrm{hPa}$, respectively) was absolutely unique and has never occurred since 1979 (start of the OWLK calculation by DWD). The code XX here mirrors the weak wind speed in the lower troposphere as a peculiarity of STE16, while M reflects the relatively high humidity. However, OWLK was not designed especially for the detection of conditions conducive to thunderstorms. Therefore, a new classification scheme (conOWLK) optimized with respect to convection was developed, yielding specific convectionfavoring weather patterns, which coincide with a very high probability of severe thunderstorm events. Additionally, a discriminant model (qdaOWLK) was applied, which provides a measure for a generally high convective predisposition in a less strict sense. According to qdaOWLK, we estimated that less than $1 \%$ of all clusters termed as convective exceeded a length of 10 days. Thus, the 11-day cluster of STE16 has to be considered as highly exceptional.

A potential weakness of our research is that the examinations mainly rely on gridded REGNIE $24 \mathrm{~h}$ totals and different proxies for convection, which both have low spatial and temporal resolution. However, high-resolution data sets such as radar, satellite, or lightning data are not available over a sufficiently long period of at least 30 years. In case of REGNIE data, it has to be considered that the regionalization approach and the limited number of stations lead to a spatial smoothing of the rain fields. Consequently, local rain maxima are underestimated by REGNIE. However, this underestimation is of systematic nature and affects all years, making long-term statistics also reasonable for convective rainfall. In terms of convective parameters and weather patterns, we are aware that those proxies do not allow establishment of a direct link to individual convective systems. For statistical analyses, however, these data sets have a suitable prediction skill, as has been shown by various studies (e.g., Haklander and van Delden, 2003; Brooks et al., 2003; Kunz, 2007; Mohr and Kunz, 2013).

For the question of whether climate change was a driver of STE16, as was frequently asked in the aftermath by the media, it is important to note that the severe thunderstorms were triggered in an environment with moderate temperatures around $20-25^{\circ} \mathrm{C}$. Thus, the potential relation between temperature increase, moisture increase, and a shift in the distributions of CAPE or SLI as shown, for example, by Mohr and Kunz (2013), does not apply to the STE16 event. In our opinion, the large annual and interannual variability of convective activity across Germany and Europe visible in the time series of all proxies investigated matter much more. The drivers of this variability, however, are not yet well understood.

In the next step we intend to scrutinize the reasons that are most decisive for the temporal variability of severe convective storms and related atmospheric conditions and to separate dynamical and thermodynamical processes. The first results showing a clear relation between thunderstorm days in several European regions and the North Atlantic Oscillation (NAO) index are promising.

\section{Data availability}

REGNIE and station precipitation data used in this paper are freely available for research and can be requested at DWD (doi:10.1127/0941-2948/2013/0436); OWLK data 
are freely available from the DWD website. CoastDatII reanalyses with an hourly resolution were produced by HZG; 2-D data can be downloaded via the ECRA database (doi:10.1594/WDCC/coastDat-2_COSMO-CLM); 3-D data can be requested from HZG (www.coastdat.de/). Sounding data are freely available from the Integrated Global Radiosonde Archive (https://www.ncdc.noaa.gov/data-access/ weather-balloon/integrated-global-radiosonde-archive).

NCEP Climate Forecast System Version 2 (CFSv2) 6-hourly Products (doi:10.5065/D61C1TXF) can be downloaded from http://rda.ucar.edu/datasets/ds094.0. Lightning data (EUCLID) are not freely available, but can be requested from Siemens BLIDS (http://blids.de).

Acknowledgements. The Center for Disaster Management and Risk Reduction Technology (CEDIM) is an interdisciplinary research center in the field of disaster management funded by the Karlsruhe Institute of Technology (KIT). The authors thank the German Weather Service (DWD), Siemens (BLIDS), and the Integrated Global Radiosonde Archive (IGRA) for providing different observational data sets. The coastDat 2 simulations were performed by Helmholtz-Zentrum Geesthacht (HZG, thanks to Beate Geyer) using the National Centers for Environmental Prediction-National Center for Atmospheric Research global reanalysis (NCEP/NCAR1). Parts of this work were funded by the Climate Initiative REKLIM of the Helmholtz Association (Germany). We acknowledge support from the German Research Foundation (DFG) and Open Access Publishing Fund of KIT. We thank the two anonymous reviewers for their comments, which helped to improve the quality of the paper.

The article processing charges for this open-access

publication were covered by a Research

Centre of the Helmholtz Association.

Edited by: V. Kotroni

Reviewed by: two anonymous referees

\section{References}

Bissolli, P. and Dittmann, E.: The objective weather type classification of the German Weather Service and its possibilities of application to environmental and meteorological investigations, Meteorol. Z., 10, 253-260, 2001.

Bissolli, P., Grieser, J., Dotzek, N., and Welsch, M.: Tornadoes in Germany 1950-2003 and their relation to particular weather conditions, Global Planet. Change, 57, 124-138, 2007.

Brooks, H. E., Lee, J. W., and Craven, J.: The spatial distribution of severe thunderstorm and tornado environments from global reanalysis data, Atmos. Res., 67, 73-94, 2003.

Croci-Maspoli, M., Schwierz, C., and Davies, H.: A multifaceted climatology of atmospheric blocking and its recent linear trend, J. Climate, 20, 633-649, 2007.

Daniell, J., Kron, A., Brand, J., Piper, D., Mühr, B., Ehmele, F., Mohr, S., and Kunz, M.: Exceptional sequence of severe thunderstorms and related flash floods in May and June 2016 in Ger- many - Part 2: Flash flood occurrences in Baden-Wuerttemberg, Nat. Hazards Earth Syst. Sci. Discuss., in preparation, 2016.

Davis, R. E., Stanmeyer, T. M., and Jones, G. V.: A synoptic climatology of tornadoes in Virginia, Phys. Geogr., 18, 383-400, 1997.

Dittmann, E.: Objektive Wetterlagenklassifikation, Tech. rep., Berichte des Deutschen Wetterdienstes, Bd. 197, Selbstverlag des Deutschen Wetterdienstes, Offenbach, Germany, 1995.

Dotzek, N., Groenemeijer, P., Feuerstein, B., and Holzer, A. M.: Overview of ESSL's severe convective storms research using the European Severe Weather Database ESWD, Atmos. Res., 93, 575-586, 2009.

Drüe, C., Hauf, T., Finke, U., Keyn, S., and Kreyer, O.: Comparison of a SAFIR lightning detection network in northern Germany to the operational BLIDS network, J. Geophys. Res.-Atmos., 112, D18114, doi:10.1029/2006JD007680, 2007.

Durre, I., Vose, R. S., and Wuertz, D. B.: Overview of the integrated global radiosonde archive, J. Climate, 1151, 53-68, 2006.

DWD: The objective weather type classification, Deutscher Wetterdienst, Offenbach, Germany, available at: https: //www.dwd.de/EN/ourservices/wetterlagenklassifikation/ wetterlagenklassifikation.html, last access: 1 August 2016.

Fisher, R. A. and Tippett, L. H. C.: Limiting forms of the frequency distribution of the largest or smallest member of a sample, Math. Proc. Cambridge Philos. Soc., 24, 180-190, 1928.

GDV: Elvira, Friederike and Co. verursachen Schäden von 1,2 Milliarden Euro, available at: http://www.gdv.de/2016/06/ elvira-friederike-co-verursachen-schaeden-von-12-milliarden-euro/, press release, last access: 4 August 2016.

Geyer, B.: High-resolution atmospheric reconstruction for $\mathrm{Eu}-$ rope 1948-2012: coastDat2, Earth Syst. Sci. Data, 6, 147-164, doi:10.5194/essd-6-147-2014, 2014.

Geyer, B. and Rockel, B.: coastDat-2 COSMO-CLM Atmospheric Reconstruction, World Data Center for Climate, doi:10.1594/WDCC/coastDat-2_COSMO-CLM, 2013.

Gumbel, E. J.: Statistics of Extremes, Columbia University Press, New York, USA, 1958.

Haklander, A. J. and van Delden, A.: Thunderstorm predictors and their forecast skill for the Netherlands, Atmos. Res., 67-68, 273299, 2003.

Hess, P. and Brezowsky, H.: Katalog der Grosswetterlagen Europas, Tech. Rep. 113, Berichte des Deutschen Wetterdienstes, Selbstverlag des Deutschen Wetterdienstes, Offenbach, Germany, 1977.

Kalnay, E., Kanamitsu, M., Kistler, R., Collins, W., Deaven, D., Gandin, L., Iredell, M., Saha, S., White, G., Woollen, J., Zhu, Y., Leetmaa, A., Reynolds, R., Chelliah, M., Ebisuzaki, W., Higgins, W., Janowiak, J., Mo, K. C., Ropelewski, C., Wang, J., Jenne, R., and Joseph, D.: The NCEP/NCAR 40-Year Reanalysis Project, B. Am. Meteorol. Soc., 77, 437-471, 1996.

Kapsch, M. L., Kunz, M., Vitolo, R., and Economou, T.: Longterm variability of hail-related weather types in an ensemble of regional climate models, J. Geophys. Res., 117, D15107, doi:10.1029/2011JD017185, 2012.

Kunz, M.: The skill of convective parameters and indices to predict isolated and severe thunderstorms, Nat. Hazards Earth Syst. Sci., 7, 327-342, doi:10.5194/nhess-7-327-2007, 2007.

Kunz, M., Mühr, B., Kunz-Plapp, T., Daniell, J. E., Khazai, B., Wenzel, F., Vannieuwenhuyse, M., Comes, T., Elmer, F., 
Schröter, K., Fohringer, J., Münzberg, T., Lucas, C., and Zschau, J.: Investigation of superstorm Sandy 2012 in a multidisciplinary approach, Nat. Hazards Earth Syst. Sci., 13, 2579 2598, doi:10.5194/nhess-13-2579-2013, 2013.

Manzato, A.: A climatology of instability indices derived from Friuli Venezia Giulia soundings, using three different methods, Atmos. Res., 67, 417-454, 2003.

Marinell, G.: Multivariate Verfahren: Einführung für Studierende und Praktiker, Oldenbourg Wissenschaftsverlag, Munich, Germany, 1998.

Masato, G., Hoskins, B. J., and Woollings, T.: Winter and summer Northern Hemisphere blocking in CMIP5 models, J. Climate, 26, 7044-7059, 2013.

Mohr, S. and Kunz, M.: Recent trends and variabilities of convective parameters relevant for hail events in Germany and Europe, Atmos. Res., 123, 211-228, 2013.

Mohr, S., Kunz, M., and Keuler, K.: Development and application of a logistic model to estimate the past and future hail potential in Germany, J. Geophys. Res.-Atmos., 120, 3939-3956, 2015.

MunichRe: Loss review for the first half of 2016: Storms and earthquakes drive losses up, available at: https://www.munichre. com/site/corporate/get/params_E-1709745365_Dattachment/ 1239057/MR-PR-NatCat-HY2016.pdf, press release, last access: 4 August 2016.

Petrow, T., Zimmer, J., and Merz, B.: Changes in the flood hazard in Germany through changing frequency and persistence of circulation patterns, Nat. Hazards Earth Syst. Sci., 9, 1409-1423, doi:10.5194/nhess-9-1409-2009, 2009.

Philipp, A., Bartholy, J., Beck, C., Erpicum, M., Esteban, P., Fettweis, X., Huth, R., James, P., Jourdain, S., Kreienkamp, F., Krennert, T., Lykoudis, S., Michalides, S. C., PiankoKluczynska, K., Post, P., Alvarez, D. R., Schiemann, R., Spekat, A., and Tymvios, F. S.: Cost733cat - A database of weather and circulation type classifications, Phys. Chem. Earth, 35, 360-373, 2010.

Rauthe, M., Steiner, H., Riediger, U., Mazurkiewicz, A., and Gratzki, A.: A Central European precipitation climatology - Part I: Generation and validation of a high-resolution gridded daily data set (HYRAS), Meteorol. Z., 22, 235-256, 2013.

Rockel, B., Will, A., and Hense, A.: The Regional Climate Model COSMO-CLM (CCLM), Meteorol. Z., 17, 347-348, 2008.

Saha, S., Moorthi, S., Pan, H. L., Wu, X., Wang, J., Nadiga, S., Tripp, P., Kistler, R., Woollen, J., Behringer, D., , Liu, H., Stokes, D., Grumbine, R., Gayno, G., Wang, J., Hou, Y.-T., Chuang, H.Y., Juang, H.-M. H., Sela, J., Iredell, M., Treadon, R., Kleist, D., van Delst, P., Keyser, D., Derber, J., Ek, M., Meng, J., Wei, H., Yang, R., Lord, S., van den Dool, H., Kumar, A., Wang, W., Long, C., Chelliah, M., Xue, Y., Huang, B., Schemm, J.-K., Ebisuzaki, W., Lin, R., Xie, P., Chen, M., Zhou, S., Higgins, W., Zou, C.-Z., Liu, Q., Chen, Y., Han, Y., Cucurull, L., Reynolds, R. W., Rutledge, G., and Goldberg, M.: The NCEP climate forecast system reanalysis, B. Am. Meteorol. Soc., 91, 1015-1057, 2010.
Saha, S., Moorthi, S., Wu, X., Wang, J., Nadiga, S., Tripp, P., Behringer, D., Hou, Y., Chuang, H., Iredell, M., Ek, M., Meng, J., Yang, R., Mendez, M. P., van den Dool, H., Zhang, Q., Wang, W., Chen, M., and Becker, E.: updated daily. NCEP Climate Forecast System Version 2 (CFSv2) 6-hourly Products, Research Data Archive at the National Center for Atmospheric Research, Computational and Information Systems Laboratory, doi:10.5065/D61C1TXF, 2011.

Saha, S., Moorthi, S., Wu, X., Wang, J., Nadiga, S., Tripp, P., Pan, H. L., Behringer, D., Hou, Y. T., Chuang, H. Y., Iredell, M., Ek, M., Meng, J., and Rongqian Yang, R.: The NCEP Climate Forecast System Version 2, J. Climate, 27, 2185-2208, 2014.

Sánchez, J. L., Fraile, R., de la Fuente, M. T., and de la Marcos, J. L.: Discriminant analysis applied to the forecasting of thunderstorms, Meteorol. Atmos. Phys., 68, 187-195, 1998.

Schröter, K., Kunz, M., Elmer, F., Mühr, B., and Merz, B.: What made the June 2013 flood in Germany an exceptional event? A hydro-meteorological evaluation, Hydrol. Earth Syst. Sci., 19, 309-327, doi:10.5194/hess-19-309-2015, 2015.

Schulz, W., Diendorfer, G., Pedeboy, S., and Poelman, D. R.: The European lightning location system EUCLID - Part 1: Performance analysis and validation, Nat. Hazards Earth Syst. Sci., 16, 595-605, doi:10.5194/nhess-16-595-2016, 2016.

Wanner, H., Rickli, R., Salvisberg, E., Schmutz, C., and Schüepp, M.: Global climate change and variability and its influence on alpine climate - concepts and observations, Theor. Appl. Climatol., 58, 221-243, 1997.

Wilks, D. S.: Statistical methods in the atmospheric sciences: An introduction, Academie Press, San Diego, California, USA, 1995.

Wussow, G.: Untere Grenzwerte dichter Regenfälle, Meteorol. Z., 39, 173-178, 1922.

Yeo, I.-K. and Johnson, R. A.: A new family of power transformations to improve normality or symmetry, Biometrika, 87, 954959, 2000. 